\title{
Site-Directed Mutagenesis
}

\author{
Nida Tabassum Khan \\ Department of Biotechnology, Faculty of Life Sciences and Informatics, Balochistan University of Information \\ Technology Engineering and Management Sciences ,(BUITEMS), Quetta, Pakistan
}

*Corresponding Author: Nida Tabassum Khan, Department of Biotechnology, Faculty of Life Sciences and Informatics, Balochistan University of Information Technology Engineering and Management Sciences,(BUITEMS), Quetta, Pakistan

\begin{abstract}
Site-directed mutagenesis is the fundamental basis of genetic modifications of DNA sequences .it helps to introduce precise genetic variations at specific sites. Kunkel method and DNA Cassette mutagenesis are the most widely used cost effective simplest approaches for producing site directed mutagenesis in target DNA.
\end{abstract}

Keywords: Kunkel Method; DNA Cassettes; Uracil.

\section{INTRODUCTION}

Mutagenesis is a molecular mechanism that deliberately creates specific alterations in the nucleotide or amino acid sequence of a DNA or protein molecule. It is employed to determine the biological structural and functional activity of macromolecules such as proteins and nucleic acids. Such position specific alteration in a target protein or DNA sequence either by means of insertion, deletion or substitution of a specific base pair aimed to produce single or multiple point mutations is termed sitedirected mutagenesis[1].Site-directed mutagenesis is the fundamental basis of genetic modifications of DNA sequences it helps to introduce precise genetic variations at specific sites in a PCR based process and the mutant construct is then cloned into the desirable vector system [2].

\section{APPROACHES OF SITE-DIRECTED MUTAGENESIS}

\subsection{Kunkel Method}

It is a classical approach for introducing single or multiple base pair substitutions, deletions or insertions in the target DNA sequence. Transformation rate is observed to be high in this approach in comparison with conventional method because wild-type DNA containing uracil is transformed into ung + strain causing the resultants to be obtainedfrom strands that lacks uracil [3].

Kunkel method is carried out in three main steps which are follows:

\section{Step1: In Vivo Process}

Plasmid containing the target sequenceis placed to be mutated into an E.coli strain that lacks uracil deglycosidase and dUTPase (ung- dut- strain). Bacteria lacking dUTPase accumulate dUTP while bacteria lacking uracil deglycosidase are unable to eliminate the incorporated dUTP that is a part of new DNA strand. As a result the plasmid is transformed into DNA that contains U's instead of T's.

\section{Step2: In Vitro Process}

Target DNA containing uracil is placed with a synthetic oligothat does not pair at the location of the desired mutation. The mixture is then preserved with dNTP's and Klenow fragments. Later DNA ligases and ATP forms the plasmid containing uracil in one strand and the other containing only T.

\section{Step3: In Vivo Process}

The hybrid DNA is transformed in bacteria by degrading the older DNA strand containing uracilto produce a strand containing $\mathrm{T}$ using the new and mutagenized DNA strand as a template. Thus, all the plasmids will contain the newly mutated sequence [3].Large fragments of DNA for this approach are 
not suitable because of their instability in a single stranded phage vector system and in addition increases the probability of mispriming by the mutagenic primer. Therefore it is advisable to use DNA fragments $>1 \mathrm{~kb}$ [4].it also provides an easy and cheaper way to sequence the target DNA at the end of mutagenesis to determine the presence of desired mutation $[5,6]$. In order to find uracil, single stranded DNA is tested for its potential to transform a dut- ung- strain efficiently but not an ung+ strain. A negative control is also introduced in the reaction without the oligonucleotide to see whether transformation yields transformants or not. This method of site directed mutagenesis is simpler and cheaper but due to high background mutagenesis efficiency is low [7, 8].

\section{Synthetic DNA Cassettes Method}

In this approach a restriction fragment is replaced in the cloned DNA by another fragment containing the desired sequence. Restriction endonucleases cleaves the cloned DNA to produce fragment of DNA containing the wild-type sequence. Generation of mutant sequence from two opposite oligonucleotides by hybridization. Synthetic fragments DNA ends should be similar as in the wild type so as to return into the vector. The remnants of the cloned DNA in the vector is mixed with the synthetic fragment, and then ligated by enzyme DNA ligase from bacteriophage T4.Ligated DNA is then introduced into competent E. coli cells and followed by the selection of the transformants [9, 10].Cassette mutagenesis efficiencyis almost $100 \%$ but the problem with this method is the absence of recognition sites in the target DNA fragment. A number of modification have been made in this method for example randomization of two or three positions by oligonucleotide cassette mutagenesis, selected for functional protein and then sequenced to find out the spectrum of allowable substitutions at each position [11]. On the other hand codon cassette mutagenesis places single codons at specific sites in target DNA.This method allows easy screening of the transformants by simply sequencing the resultant plasmids and offers flexibility to perform multiple cassettes on the same vector once set up with flanking restriction sites. Since this approach does not require the use of primers therefore is cheaper than kunkel method. However cassette mutagenesis may sometime causes doubling or deletion of mutants to be produced .Therefore it requires to insert appropriate restriction sites for exchanging cassettes. This method also requires SapI restriction enzyme cut sites, and other cut sites flanking the target region for removal of DNA and works best when target region is contained in a small DNA fragments [12].

\section{CONCLUSION}

Thus both methods mentioned above could be used to produce site directed mutagenesis in the target DNA molecules.

\section{REFERENCES}

[1] Jacobson, J., \& Chu, L. L. Y. (2015). U.S. Patent No. 9,217,144. Washington, DC: U.S. Patent and Trademark Office.

[2] Zheng, L., Baumann, U., \& Reymond, J. L. (2004). An efficient one-step site-directed and site-saturation mutagenesis protocol. Nucleic acids research, 32(14), e115-e115.

[3] Kunkel, T. A. (1985). Rapid and efficient site-specific mutagenesis without phenotypic selection. Proceedings of the National Academy of Sciences, 82(2), 488-492.

[4] http://www.bio.davidson.edu/courses/molbio/kunkel/kunkel.html

[5] Guide, M. A. Ultramer ${ }^{\mathrm{TM}}$ Oligonucleotides.

[6] Shortle, D., DiMaio, D., \& Nathans, D. (1981). Directed mutagenesis. Annual review of genetics, 15(1), 265-294.

[7] Vandeyar, M. A., Weiner, M. P., Hutton, C. J., \& Batt, C. A. (1988). A simple and rapid method for the selection of oligodeoxynucleotide-directed mutants. Gene, 65(1), 129-133.

[8] Sugimoto, M., Esaki, N., Tanaka, H., \& Soda, K. (1989). A simple and efficient method for the oligonucleotide-directed mutagenesis using plasmid DNA template and phosphorothioate-modified nucleotide. Analytical biochemistry, 179(2), 309-311

[9] Wells, J. A., Vasser, M., \& Powers, D. B. (1985). Cassette mutagenesis: an efficient method for generation of multiple mutations at defined sites. Gene, 34(2), 315-323.

[10] http://what-when-how.com/molecularbiology/site-directed-mutagenesis-part-1-molecular-biology/ 
[11] Estell, D. A., Graycar, T. P., \& Wells, J. A. (1985). Engineering an enzyme by site-directed mutagenesis to be resistant to chemical oxidation. Journal of Biological Chemistry, 260(11), 6518-6521

[12] Papworth, C., Bauer, J. C., Braman, J., \& Wright, D. A. (1996). Site-directed mutagenesis in one day with> $80 \%$ efficiency. Strategies, 9(4).

Citation: N. Tabassum Khan, "Site-Directed Mutagenesis", International Journal of Research Studies in Biosciences (IJRSB), vol. 5, no. 10, pp. 7-9, 2017. http://dx.doi.org/10.20431/2349-0365.0510002

Copyright: (C) 2017 Authors. This is an open-access article distributed under the terms of the Creative Commons Attribution License, which permits unrestricted use, distribution, and reproduction in any medium, provided the original author and source are credited. 